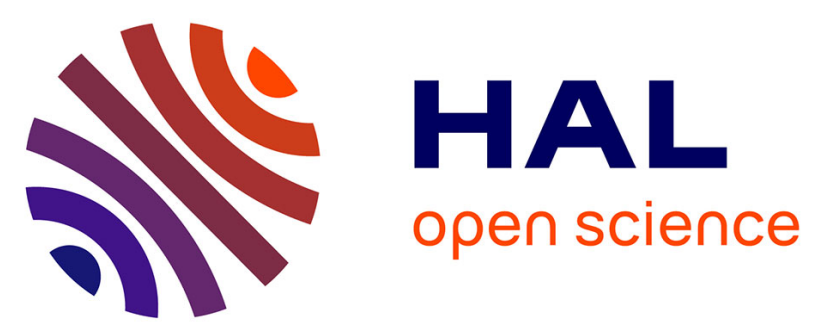

\title{
Isolation and characterization of Bradyrhizobium sp. SR1 degrading two $\beta$-triketone herbicides
}

\author{
Sana Romdhane, Marion Devers-Lamrani, Fabrice Martin-Laurent, \\ Christophe Calvayrac, Emilie Rocaboy-Faquet, David Riboul, Jean-François \\ Cooper, Lise Barthelmebs
}

\section{To cite this version:}

Sana Romdhane, Marion Devers-Lamrani, Fabrice Martin-Laurent, Christophe Calvayrac, Emilie Rocaboy-Faquet, et al.. Isolation and characterization of Bradyrhizobium sp. SR1 degrading two $\beta$-triketone herbicides. Environmental Science and Pollution Research, 2015, 23 (5), pp. 1-11. 10.1007/s11356-015-4544-1 . hal-01204955

\section{HAL Id: hal-01204955 \\ https://hal.science/hal-01204955}

Submitted on 24 Sep 2015

HAL is a multi-disciplinary open access archive for the deposit and dissemination of scientific research documents, whether they are published or not. The documents may come from teaching and research institutions in France or abroad, or from public or private research centers.
L'archive ouverte pluridisciplinaire HAL, est destinée au dépôt et à la diffusion de documents scientifiques de niveau recherche, publiés ou non, émanant des établissements d'enseignement et de recherche français ou étrangers, des laboratoires publics ou privés. 


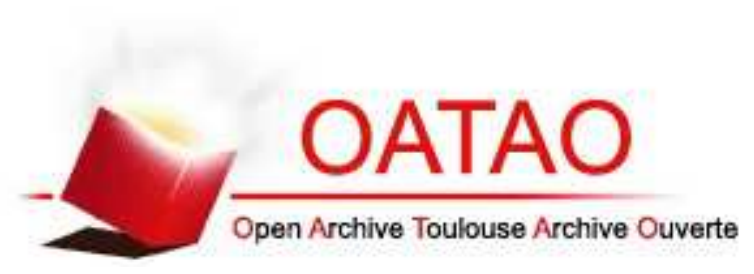

\section{Open Archive TOULOUSE Archive Ouverte (OATAO)}

OATAO is an open access repository that collects the work of Toulouse researchers and makes it freely available over the web where possible.

This is an author-deposited version published in : http://oatao.univ-toulouse.fr/ Eprints ID : 14005

To link to this article : DOI:10.1007/s11356-015-4544-1

URL : $\underline{\text { http://dx.doi.org/10.1007/s11356-015-4544-1 }}$

To cite this version : Romdhane, Sana and Devers-Lamrani, Marion and Martin-Laurent, Fabrice and Calvayrac, Christophe and Rocaboy-Faquet, Emilie and Riboul, David and Cooper, JeanFrançois and Barthelmebs, Lise Isolation and characterization of Bradyrhizobium sp. SR1 degrading two $\beta$-triketone herbicides. (2015) Environmental Science and Pollution Research. ISSN 09441344

Any correspondence concerning this service should be sent to the repository administrator: staff-oatao@listes-diff.inp-toulouse.fr 


\title{
Isolation and characterization of Bradyrhizobium sp. SR1 degrading two $\beta$-triketone herbicides
}

\author{
Sana Romdhane ${ }^{1,2,3}$ - Marion Devers-Lamrani ${ }^{3} \cdot$ Fabrice Martin-Laurent $^{3}$. \\ Christophe Calvayrac $^{2}$ - Emilie Rocaboy-Faquet ${ }^{1}$ - David Riboul ${ }^{4,5}$. \\ Jean-François Cooper ${ }^{2}$ - Lise Barthelmebs ${ }^{1}$
}

\begin{abstract}
In this study, a bacterial strain able to use sulcotrione, a $\beta$-triketone herbicide, as sole source of carbon and energy was isolated from soil samples previously treated with this herbicide. Phylogenetic study based on16S rRNA gene sequence showed that the isolate has $100 \%$ of similarity with several Bradyrhizobium and was accordingly designated as Bradyrhizobium sp. SR1. Plasmid profiling revealed the presence of a large plasmid ( $>50 \mathrm{~kb})$ in SR1 not cured under nonselective conditions. Its transfer to Escherichia coli by electroporation failed to induce $\beta$-triketone degrading capacity, suggesting that degrading genes possibly located on this plasmid cannot be expressed in E. coli or that they are not plasmid borne. The evaluation of the SR1 ability to degrade various synthetic (mesotrione and tembotrione) and natural (leptospermone) triketones showed that this strain was also able to degrade mesotrione. Although SR1 was able to entirely
\end{abstract}

1 Biocapteurs Analyses Environnement (BAE), University of Perpignan Via Domitia, 66860 Perpignan, France

2 Laboratoire de Chimie des Biomolécules et de l'EnvironnementCRIOBE-USR 3278 CNRS EPHE, University of Perpignan Via Domitia, 66860 Perpignan, France

3 INRA, UMR 1347 Agroécologie, Pole Ecoldur, 17 rue Sully, BP 86510, 21065 Dijon Cedex, France

4 INPT, ENSIACET, Université de Toulouse, 31432 Toulouse, France

5 Laboratoire de Génie Chimique (LGC UMR 5503), CNRS, 4 allée Emile Monso, BP 84234, 31432 Toulouse, France dissipate both herbicides, degradation rate of sulcotrione was ten times higher than that of mesotrione, showing a greater affinity of degrading-enzyme system to sulcotrione. Degradation pathway of sulcotrione involved the formation of 2-chloro-4-mesylbenzoic acid (CMBA), previously identified in sulcotrione degradation, and of a new metabolite identified as hydroxy-sulcotrione. Mesotrione degradation pathway leads to the accumulation of 4-methylsulfonyl-2-nitrobenzoic acid (MNBA) and 2-amino-4 methylsulfonylbenzoic acid (AMBA), two well-known metabolites of this herbicide. Along with the dissipation of $\beta$-triketones, one could observe the decrease in 4-hydroxyphenylpyruvate dioxygenase (HPPD) inhibition, indicating that toxicity was due to parent molecules, and not to the formed metabolites. This is the first report of the isolation of bacterial strain able to transform two $\beta$-triketones.

Keywords $\beta$-Triketone $\cdot$ Sulcotrione $\cdot$ Mesotrione Biodegradation · Bradyrhizobium sp. SR1

\section{Introduction}

The widespread use of herbicides over the last decades to control weeds and to ensure quality and high crop yields led to the contamination of the environment. Among popular plant protection products, $\beta$-triketones, which replaced atrazine banned in several European countries (Chaabane et al. 2008; Calvayrac et al. 2012), are used as selective pre- and postemergence herbicides for a wide range of broad-leaved and grass weeds in maize (Mitchell et al. 2001). Sulcotrione (2-[2-chloro4-(methylsulfonyl)benzoyl]-1,3-cyclohexanedione) and mesotrione (2-[4-(methylsulfonyl)-2-nitrobenzoyl]-1,3cyclohexanedione) (Fig. 1) released in 1993 and 2003, respectively, are chemically derived from leptospermone, a natural 
Fig. 1 Molecular structure of $\beta$ triketones herbicides<smiles>COc1ccc(C(=O)C2C(=O)CCCC2=O)c(Cl)c1</smiles>

Sulcotrione

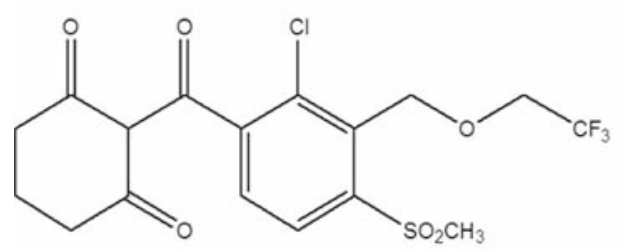

Tembotrione<smiles>COc1ccc(C(=O)C2C(=O)CCCC2=O)c([N+](=O)[O-])c1</smiles>

Mesotrione<smiles>CC(C)CC(=O)C1C(=O)C(C)(C)C(=O)C(C)(C)C1=O</smiles>

Leptospermone phytotoxin of the Californian bottlebrush plant, Callistemon spp. (Dayan et al. 2007). The target site for triketone herbicides was identified as the enzyme $p$-hydroxyphenylpyruvate dioxygenase (HPPD), which is found in a wide range of eukaryotic and prokaryotic organisms being involved in the catabolism of tyrosine. In plants, this enzyme catalyzes the conversion of $p$-hydroxyphenyl pyruvate (HPP) to homogentisate, which is the biosynthesis precursor of plastoquinone and $\alpha$ tocopherol (Schulz et al. 1993; Lee et al. 1997; Meazza et al. 2002; Rocaboy et al. 2014). HPPD inhibition causes disruption of carotenoids biosynthesis and results in foliage bleaching of treated plants. All triketones are HPPD competitive inhibitors that form a tight complex with the enzyme by a mechanism of coordination to the active-site iron atom. Maize is known to exhibit natural tolerance to triketones using a nontarget mechanism based on rapid metabolic detoxification, involving a ring hydroxylation by the cytochrome P450 monooxygenase (P450), associated to a less sensitive form of the maize HPPD to triketones (Mitchell et al. 2001; Siehl et al. 2014).

Several works have detailed the environmental profile of triketone herbicides. Half-life $\left(\mathrm{DT}_{50}\right)$ in field varies between 16 and 122 days for sulcotrione and 6 and 34 days for mesotrione, depending on $\mathrm{pH}$ and organic matter content of soil (Rouchaud et al. 1998; Dyson et al. 2002; Chaabane et al. 2005; Crouzet et al. 2010). Although these herbicides are considered to have a favorable environmental and toxicological profiles (Shaner 2004), these molecules are of concern due to their potential toxicity for any living organisms harboring HPPD enzyme (Schulz et al. 1993; Wu et al. 2011; Joly et al. 2013). The toxicity of sulcotrione and mesotrione has been demonstrated on model organisms, such as Tetrahymena pyriformis and Vibrio fischeri (Microtox ${ }^{\circledR}$ bioassay). These two herbicides showed a toxicity level equal to or higher than atrazine (Bonnet et al. 2008; Joly et al. 2013). Recently, higher cytotoxicity and genotoxicity of sulcotrione mixture after photodegradation were shown in Allium cepa test as compared to the parent molecule (Goujon et al. 2014).

Microbial degradation is considered as the major dissipation process limiting the accumulation of pesticides in the environment (Anderson 1984; Walker and Welch 1991; Topp 2003; Arbeli and Fuentes 2007). For a range of pesticides, their repeated application was shown to lead to the selection of microbial populations able to use them as sources of nutrients and energy for their growth. This phenomenon is relying on the acquisition of degradation capacities through genetic mechanisms such as horizontal transfer, mutation, and genetic rearrangements (van der Meer et al. 1992). To date, only few papers reported the isolation and the characterization of bacterial strains able to degrade the two synthetic $\beta$ triketones. To our best knowledge, only one bacterial strain identified as Pseudomonas sp. 1OP has been found to be able to degrade sulcotrione (Calvayrac et al. 2012, 2014). Two Bacillus sp. strains isolated from agricultural soil and cloud water (Durand et al. 2006; Batisson et al. 2009) have been shown to completely and rapidly degrade mesotrione. A new mesotrione-degrading bacteria isolated from aquatic environment was identified as Pantoea ananatis (Pileggi et al. 2012). Contrary to the two Bacillus sp. strains, mesotrione was not a carbon source to $P$. ananatis, and glucose was required to start growth and degradation, suggesting a cometabolic process. Recently, Escherichia coli DH5- $\alpha$ was shown to possess a mechanism of adaptation to mesotrione involving glutathione-S-transferase (GST) enzyme (Olchanheski et al. 2014). Similarly to P450, GST enzymes have been commonly characterized in plants as nontarget based mechanisms for herbicide resistance $(\mathrm{Ma}$ et al. 2013). Then, E. coli DH5- $\alpha$ mesotrione degradation could be considered as an oxidative and nonspecific stress response. Until now, nothing is known about catabolic genes involved in sulcotrione and mesotrione degradation. 
In this study, we report the isolation of a sulcotrionedegrading bacterial strain from an agricultural soil. Taxonomic and genetic characterization of the bacterial isolate was performed by $16 \mathrm{~S}$ rRNA sequencing, plasmid profiling, and cloning. The capacity of the strain to degrade aerobically a range of synthetic (mesotrione, tembotrione) and natural (leptospermone) $\beta$-triketones was estimated. Metabolic pathways of sulcotrione and mesotrione were also investigated. The toxicity of these two herbicides and their related metabolites was estimated using HPPD inhibition test.

\section{Materials and methods}

\section{Soil sampling and characteristics}

Soil was collected from the surface layer $(0-10 \mathrm{~cm})$ of an experimental field located at the University of Perpignan, France. Soil samples were sieved $(2 \mathrm{~mm})$ and stored at $4{ }^{\circ} \mathrm{C}$ until use. The composition and characteristics of the soil was $13.9 \%$ clay, $60.5 \%$ silt, $25.6 \%$ sand, $20 \%$ soil humidity, $1.7 \%$ organic matter, $0.9 \%$ organic carbon, $0.98 \mathrm{~g} . \mathrm{kg}^{-1}$ total nitrogen, 15.5 meq $100 \mathrm{~g}^{-1}$ cation exchange capacity (CEC), $214 \% \mathrm{Ca}^{2+} / \mathrm{CEC}$ and $\mathrm{pH}$ in water 8.1 .

\section{Chemicals and media}

Analytical standards of sulcotrione (98.8 \% purity) and 1,3cyclohexanedione (CHD) (97.0\% purity) were purchased from Sigma-Aldrich (France). 2-Chloro-4-mesylbenzoic acid (CMBA) $(95.0 \%$ purity) was purchased from Acros Organics (France). Standards of mesotrione and tembotrione were purchased from Dr. Ehrenstorfer GmbH (Germany) as well as mesotrione metabolites 4-methylsulfonyl-2-nitrobenzoic acid (MNBA) and 2-amino-4-methylsulfonylbenzoic acid (AMBA). Leptospermone was kindly provided by F. E. Dayan (USDA, University of Mississippi, USA). Acetonitrile, methanol, and dichloromethane (HPLC quality) were purchased from Sigma-Aldrich and hydrochloric acid (38.0 \%) from Prolabo (France).

$\beta$-Triketones solutions were prepared in water at initial concentration of $1 \mathrm{~g} \mathrm{~L}^{-1}(\mathrm{pH} 9)$. They were then sterilized using a $0.2-\mu \mathrm{m}$ filter, and finally added to mineral salts medium (MS) (Rousseaux et al. 2001) composed by: $\mathrm{K}_{2} \mathrm{HPO}_{4}$ $\left(1.6 \mathrm{~g} \mathrm{~L}^{-1}\right), \mathrm{KH}_{2} \mathrm{PO}_{4}\left(0.4 \mathrm{~g} \mathrm{~L}^{-1}\right), \mathrm{NaCl}\left(0.1 \mathrm{~g} \mathrm{~L}^{-1}\right), \mathrm{MgSO}_{4}$ $7 \mathrm{H}_{2} \mathrm{O}\left(0.2 \mathrm{~g} \mathrm{~L}^{-1}\right), \mathrm{CaCl}_{2}\left(0.02 \mathrm{~g} \mathrm{~L}^{-1}\right), \mathrm{FeSO}_{4}, 7 \mathrm{H}_{2} \mathrm{O}$ $\left(5 \mathrm{mg} \mathrm{L}^{-1}\right), \mathrm{H}_{3} \mathrm{BO}_{3}\left(2 \mathrm{mg} \mathrm{L}^{-1}\right), \mathrm{MnSO}_{4}, \mathrm{H}_{2} \mathrm{O}\left(1.8 \mathrm{mg} \mathrm{L}^{-1}\right)$, $\mathrm{ZnSO}_{4}\left(0.2 \mathrm{mg} \mathrm{L}^{-1}\right), \mathrm{CuSO}_{4}\left(0.1 \mathrm{mg} \mathrm{L}{ }^{-1}\right), \mathrm{Na}_{2} \mathrm{MoO}_{4}$ $\left(0.25 \mathrm{mg} \mathrm{L}^{-1}\right)$, biotin $\left(0.04 \mathrm{mg} \mathrm{L}^{-1}\right)$, and thiamine $\left(0.1 \mathrm{mg} \mathrm{L}^{-1}\right)$. Each $\beta$-triketone herbicide or each metabolite was used as sole carbon source in liquid MS medium. Yeast extract mannitol medium (YM) containing (per liter) $2.5 \mathrm{~g}$ of yeast extract, $0.5 \mathrm{~g}$ of $\mathrm{K}_{2} \mathrm{HPO}_{4}, 0.1 \mathrm{~g}$ of $\mathrm{NaCl}, 0.2 \mathrm{~g}$ of
$\mathrm{MgSO}_{4} \cdot 7 \mathrm{H}_{2} \mathrm{O}, 0.1 \mathrm{~g}$ of $\mathrm{CaCO}_{3}$, and $10 \mathrm{~g}$ of mannitol (Vincent 1970) and TY medium composed by (per liter) $5 \mathrm{~g}$ tryptone, $3 \mathrm{~g}$ yeast extract, and $66 \mathrm{mg} \mathrm{CaCl}{ }_{2}$ were used as a rich medium. Luria-Bertani medium (LB) [tryptone $\left(10 \mathrm{~g} \mathrm{~L}^{-1}\right)$, yeast extract $\left(5 \mathrm{~g} \mathrm{~L}^{-1}\right)$, and $\left.\mathrm{NaCl}\left(5 \mathrm{~g} \mathrm{~L}^{-1}\right)\right]$ was used for $E$. coli plating.

\section{Enrichment, isolation, and screening of microbial strains}

Enrichment of sulcotrione-degrading bacteria was performed by adding $10 \mathrm{~g}$ of soil in an Erlenmeyer flask containing $90 \mathrm{~mL}$ of sterilized MS medium supplemented with sulcotrione at a final concentration of $35 \mathrm{mg} \mathrm{L}^{-1}$ $(0.106 \mathrm{mM})$. The culture was incubated at $28^{\circ} \mathrm{C}$ with continuous shaking at $150 \mathrm{rpm}$. After five enrichments, a serial dilution of the obtained bacterial consortium was done in MS liquid in order to reduce the culture microbial diversity. The $10^{-3}-10^{-8}$ dilutions were plated on both MS-sulcotrione and TY solid medium. Plates were incubated at $28{ }^{\circ} \mathrm{C}$. Degrading capacity of dilution cultures was monitored. When about $50 \%$ of the initial sulcotrione concentration was degraded, a new dilution series was started until three to four different growing colonies were obtained on TY plates. Each isolated colony was inoculated in liquid MS-sulcotrione to assess their degrading capacity. Regularly, 1-mL aliquot was sampled to monitor sulcotrione disappearance in the culture medium. Noninoculated cultures were used as control. A pure strain degrading the sulcotrione was isolated, and named SR1.

\section{Analytical methodology}

One-milliliter aliquots of liquid culture were analyzed by high-performance liquid chromatography (HPLC) Jasco apparatus equipped with a Phenomenex Luna C18 column $(150 \times 3.0 \mathrm{~mm} ; 5 \mu \mathrm{m})$ and a diode array detector Jasco 875 UV set. The mobile phase was a mixture of water (AW) and acetonitrile (ACN) acidified by $0.1 \%$ formic acid, delivered at a flow rate of $0.5 \mathrm{~mL} \mathrm{~min}^{-1}$. A gradient method was used in order to improve molecules and metabolites separation: 0 $4 \min 70 \% \mathrm{AW}-30 \% \mathrm{~A}-\mathrm{ACN}$, from 4 to $7 \min 40 \% \mathrm{AW}-$ $60 \%$ A-ACN maintained for $15 \mathrm{~min}$, then back to $70 \% \mathrm{AW}-$ $30 \% \mathrm{~A}-\mathrm{ACN}$.

Metabolites identification was accomplished using liquid chromatography-mass spectrometry (LC-MS) methodology. Primarily, Thermo Fisher Scientific LC-MS device, Accela HPLC coupled to a LCQ Fleet equipped with an electrospray ionization source and a 3D ion-trap analyzer was used. A full scan range in both positive and negative ion mode from $\mathrm{m} / \mathrm{z} 60$ to 300 in both positive was carried out, using the following gradient system: $90 \% / 10 \%$ (AW/A-ACN) from 0 to $5 \mathrm{~min}$, then $20 \% / 80 \%(\mathrm{AW} / \mathrm{A}-\mathrm{ACN})$ maintained to $16 \mathrm{~min}$. Confirmation of the nature of sulcotrione byproducts was carried out using an LC-high-resolution mass spectrometry 
device: LC-HRMS Q Exactive hybrid quadrupole-Orbitrap mass spectrometer (Thermo Fisher). Ions were generated using an electrospray ion source (ESI), and analysis was done in both positive and negative modes. The chromatographic system was equipped with a Luna PFP $2(150 \times 2.00 \mathrm{~mm}$; $3 \mu \mathrm{m}$, Phenomenex). $0.1 \%$ formic acid in Milli-Q water, and $0.1 \%$ formic acid in ACN were used as mobile phase. The elution gradient were $3 \%$ A-ACN (5 min), 3-95\% A$\mathrm{ACN}(20 \mathrm{~min}), 95 \% \mathrm{~A}-\mathrm{ACN}(5 \mathrm{~min}), 95-3 \% \mathrm{~A}-\mathrm{ACN}$ (1 $\mathrm{min}$ ), and $3 \%$ A-ACN (5 min). Mass spectra analysis was effectuated using Xcalibur (version 2.0, Thermo Fisher) and MetAlign (version 041011, Arjen Lommen). For LC-MS analysis, aliquots were extracted from the bacterial culture medium as described by Calvayrac et al. (2012).

Purification was performed using a semi-preparative device (WATERS 1525 binary HPLC pump, Waters 248 DAD) equipped with a column ODS Uptisphere $5 \mu \mathrm{m}$. Mobile phase was a mixture of water and acetonitrile acidified by $0.1 \%$ formic acid, delivered as follows: $20 \% \mathrm{~A}-\mathrm{ACN}$ (5 min), $95 \%$ A-ACN until 22 min, then $20 \%$ A-ACN until $35 \mathrm{~min}$. The structure of sulcotrione metabolite was confirmed using 1H NMR (400 MHz, CDCl3).

\section{Characterization of a sulcotrione-degrading isolate}

Bacterial genomic DNA of SR1 strain was extracted by standard alkaline lysis method from one pure colony and used as template for PCR extraction reactions. The amplification reaction was carried out in $50 \mu \mathrm{l}$ reaction volume containing $1.25 \mathrm{U}$ of GoTaq DNA polymerase (Promega, USA) using $50 \mathrm{ng}$ of DNA as template. 16S rRNA gene was amplified using universal primers $27 \mathrm{f}$ (5'-AGA GTT TGA TCH TGG CTC AG-3') and 1492r (5'-TAC GGH TAC CTT GTT ACG ACT T-3') (Gürtler and Stanisich 1996). PCR reactions were carried out in a thermocycler (Gradient Cycler, MJ Research, USA) under the following conditions: $5 \mathrm{~min}$ at $94^{\circ} \mathrm{C}$, followed by 35 cycles at $94{ }^{\circ} \mathrm{C}$ for $1 \mathrm{~min}, 55^{\circ} \mathrm{C}$ for $1 \mathrm{~min}$ and $72{ }^{\circ} \mathrm{C}$ for $2 \mathrm{~min}$, and a $72^{\circ} \mathrm{C}$ cycle for $15 \mathrm{~min}$. The concentration of 16S rRNA amplicon was quantified using a spectrophotometer (Biophotometer, Eppendorf, Germany), and DNA quality was checked on $1 \%$ agarose gel in $1 \times$ TBE buffer. The purity of the isolated bacteria was checked by $16 \mathrm{~S}$ rRNA restriction fragment length polymorphism (RFLP). Restriction profiles were obtained by PCR products treatment using restriction enzymes $A l u \mathrm{I}$ and $R s a \mathrm{I}$ (Fermentas, France). Separation of digestion products was effectuated on high-resolution $3 \%$ agarose gel (MP Q-BIOgene, USA). DNA Molecular Weight Marker VIII (Roche Applied Science, France) was used to estimate the restriction fragments size.

16S rRNA amplicon was sequenced using the Sanger technology (Beckman Coulter Genomics). Sequence was deposited in GenBank under accession number KP683073. SR1 16S rRNA sequence was compared to closest sequences retrieved from GenBank database using the Basic Local Alignment Search Tool (BLAST) (http://www.ncbi.nlm.nih.gov/ BLAST/) of the National Center for Biotechnology Information (NCBI). For phylogenetic analysis, multiple alignments were done with ClustalX program (Thompson et al. 1997), and neighbor-joining tree was calculated with the NJPlot software (Perrière and Gouy 1996).

\section{Degradation of $\beta$-triketones herbicides by the isolated strain SR1}

Capacity of SR1 to degrade $\beta$-triketone herbicides was estimated in resting cell experiments. SR1 was grown in YM incubated at $28^{\circ} \mathrm{C}$ under agitation at $150 \mathrm{rpm}$. Bacterial culture was centrifuged at $4500 \mathrm{~g}$ for $10 \mathrm{~min}$ at $4{ }^{\circ} \mathrm{C}$. The pellet was then washed twice with MS medium and resuspended in $100 \mathrm{~mL}$ of MS containing herbicides at a concentration of $35 \mathrm{mg} \mathrm{L}^{-1}$ and an $\mathrm{OD}_{620}$ of $0.5 \mathrm{~nm}$. Aliquots were regularly collected and frozen at $-20{ }^{\circ} \mathrm{C}$ until analysis. Resting cell experiments were realized in triplicate. Noninoculated MS liquid controls supplemented either in $\beta$-triketone herbicide or in degradation product were maintained under the same conditions. As a negative control, similar experiments were carried out with four other Bradyrhizobium strains (B. japonicum USDA 110, Bradyrhizobium sp. LL13, Bradyrhizobium USDA 127, and Bradyrhizobium sp. G49) never exposed to sulcotrione.

\section{SR1 strain plasmid curing assays}

In order to establish a relationship between the degradation capacity and the presence of the plasmid, a curing experiment was carried out. The isolated strain was diluted $(1 / 100$ and 1/1000) and grown in YM medium without pesticide until the end of exponential growth phase. An aliquot was taken, and plasmid profile was done using Eckhardt method as previously described (Devers et al. 2007). Ten transfers (about 80 generations) were accomplished. Degradation capacity of the isolate was assessed after each transfer using resting cells experiment to monitor the evolution of sulcotrione-degrading ability.

\section{SR1 strain plasmid isolation and transfer}

SR1 strain was grown in YM liquid medium at $28^{\circ} \mathrm{C}$ for 3 days with shaking at $150 \mathrm{rpm}$. Fifty milliliters of the grown culture was used to extract its plasmid using the Qiagen Plasmid midi kit (Qiagen, France). The plasmid was Tn5labeled using the EZ-Tn5 ${ }^{\mathrm{TM}}<\mathrm{R} 6 \mathrm{~K} \gamma$ ori $/ \mathrm{KAN}-2>$ insertion kit (Epicentre, USA) and introduced by electroporation in E. coli TransforMax ${ }^{\mathrm{TM}} \mathrm{EC} 100 \mathrm{D}^{\mathrm{TM}}$ pir $^{+}$cells according to the manufacturer's recommendations (Epicentre, USA). Transformants harboring SR1 plasmid was cultivated 
overnight in LB medium containing Kanamycine (50 mg L ${ }^{-1}$ ). SR1 Tn5-labeled plasmid was also introduced in electrocompetent cells of Bradyrhizobium sp. G49 by electroporation. Resting cell experiments were then carried out at 37 and $28^{\circ} \mathrm{C}$, respectively, for E. coli and Bradyrhizobium sp. G49 as previously described to assess sulcotrione degradation.

\section{HPPD activity monitoring using colorimetric assay}

Aliquots, regularly collected from SR1 resting cells, incubated with $35 \mathrm{mg} \mathrm{L}^{-1}$ of sulcotrione or mesotrione were analyzed with the colorimetric free cells bioassay developed by Rocaboy et al. (2014). Aliquots were firstly centrifuged (13, $500 \mathrm{rpm}$ for $15 \mathrm{~min}$ ) to remove SR1 cells from the supernatant. Each well of the 96-well microplate was filled with 12.5 or $25 \mu \mathrm{L}$ of supernatant, and mixed with $E$. coli HPPDinduced cells and $1.2 \mathrm{mg} \mathrm{mL}^{-1}$ tyrosine. Triketone-positive controls were performed using $35 \mathrm{mg} \mathrm{L}^{-1}$ sulcotrione or mesotrione solution instead of resting cells supernatants. MS was added for controls. All tests were performed in triplicate. After $12 \mathrm{~h}$ of incubation, optical density of each well was measured at $405 \mathrm{~nm}$.

\section{Results}

\section{Isolation and characterization of sulcotrione-degrading bacteria}

Enrichment culture was conducted using the soil of Perpignan that was previously exposed to sulcotrione (Chaabane et al. 2008) and shown to have a microflora able to degrade this compound with a half-life time of 8 days (Calvayrac et al. 2012). After five enrichment cycles, a mixed bacterial culture able to degrade sulcotrione was obtained (data not shown). After serial dilution of enrichment cultures and plating on both nutrient agar TY and MS agar containing sulcotrione as the sole carbon source, four pure isolates were obtained. The evaluation of their sulcotrione-degrading capacities revealed that only one isolate named SR1 was capable of efficiently degrade sulcotrione. The purity of SR1 strain was verified using RFLP fingerprinting of PCR-amplified 16S rDNA in both rich and MS medium (data not shown). This isolate was a Gramnegative, aerobic, motile, and rod-shaped bacterium.

SR1 16S rRNA sequence (1353 bp) showed $100 \%$ of similarity with several Bradyrhizobium strains including B. elkanii strain SEMIA 6399, B. japonicum strain SEMIA 6154 and Bradyrhizobium sp. CMVU02. None of these isolates are known to degrade pollutants such as pesticides. Besides, resting cell experiments carried out with four Bradyrhizobium strains never previously exposed to sulcotrione showed that they were unable to degrade this herbicide (data not shown). Phylogenetic distances with other known triketones-degrading bacteria are presented in Fig. 2. Based on phylogenetic analysis, this isolate was named Bradyrhizobium sp. SR1. One could observe that the two known sulcotrione degraders belonged to the phylum of Proteobacteria in the $\alpha$ - and $\gamma$-Proteobacteria classes (Bradyrhizobium sp. SR1 and Pseudomonas sp. 1OP, respectively), the two mesotrione degraders belonged to the $\gamma$ Proteobacteria (E. coli DH5- $\alpha$ and P. ananatis) as well, and the two others belonged to the Firmicutes phylum (Bacillus sp. MES11 and Bacillus sp. 3B6).

\section{Degradation of sulcotrione by Bradyrhizobium sp. SR1}

Degradation kinetics of sulcotrione was established in resting cell experiments in MS medium supplemented with $35 \mathrm{mg} \mathrm{L}^{-1}$ of sulcotrione. One could observe that all the sulcotrione was completely degraded within $48 \mathrm{~h}$ in SR 1 culture, while the concentration of sulcotrione remained stable in the control indicating the chemical stability of this molecule under our conditions (Fig. 5a, Supplementary data Fig. 1-A). Sulcotrione dissipation could be described by a first-order kinetic $\left(C=120 \mathrm{e}^{-0.075 t}, R^{2}=0.913, n=3\right)$ after a lag phase estimated to about $4 \mathrm{~h}$. Half-life time was estimated to about $13 \mathrm{~h}$ (Supplementary data Fig. 1-A). During the degradation of sulcotrione by Bradyrhizobium sp. SR1, we searched for the two-known sulcotrione metabolites: CHD and CMBA. Under our experimental conditions, we did not detect CHD. However as previously reported for Pseudomonas sp. 1OP (Calvayrac et al. 2012), CMBA was identified using mass spectral in negative mode (ESI $\mathrm{m} / \mathrm{z} 234$ ) as the major metabolite. The apparition of this by-product is concomitant with the dissipation of sulcotrione with a molar recovery close to $90 \%$ all during the time course of the herbicide degradation (Fig. 3a). Concomitantly with the appearance of CMBA (after $4 \mathrm{~h}$ of incubation), we observed the formation of another metabolite having a retention time different from those of CMBA and sulcotrione ones. This metabolite cannot be detected anymore when the sulcotrione was fully dissipated (Supplementary data Fig. 1-A). The LC-MS analysis corresponding to this peak (ESI $\mathrm{m} / \mathrm{z} 343$ ) allowed us to propose hydroxy-sulcotrione as an intermediate metabolite of sulcotrione that finally gives CMBA (Fig. 4). In order to confirm this hypothesis, the metabolite was purified by semipreparative chromatography from a large amount of SR1 resting cells prepared in MS-sulcotrione medium. Analysis of the metabolite in high-resolution LC-MS revealed the presence of a hydroxyl group on $\alpha$-carbon of the carbonyl functional group. Additional proton NMR analysis of the purified metabolite clearly confirmed the absence of the hydroxyl group on the aromatic ring. Further resting cell experiments showed that SR1 was not able to degrade CMBA and CHD.

Resting cell experiments were also performed with higher concentrations of sulcotrione $\left(100,200\right.$, and $\left.400 \mathrm{mg} \mathrm{L}^{-1}\right)$. 


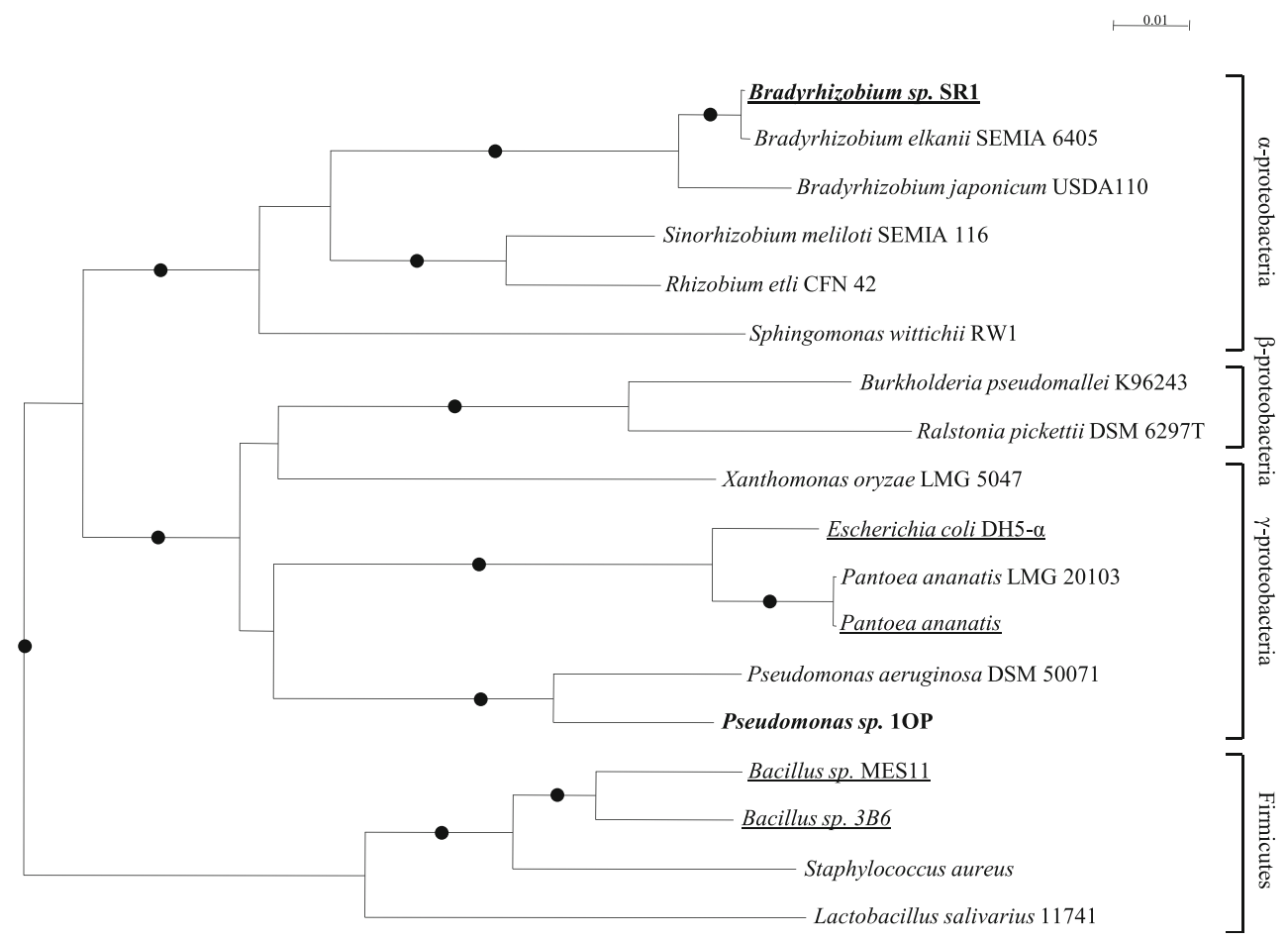

Fig. 2 Neighbor-joining phylogenetic analysis based on the multiple alignment of 16S rRNA sequences of Bradyrhizobium sp. SR1 with sulcotrione degrading strains (marked in bold), mesotrione degrading strains (underlined), and nondegrading strains. Nonavailable 16S rRNA sequences were replaced by their closest relative. Bootstrap values higher than 900 iterations out of 1000 are marked as black circles. Accession numbers of used strains are Bradyrhizobium sp. SR1 (KP683073), Bradyrhizobium elkanii strain SEMIA 6405 (FJ025109.1), Bradyrhizobium japonicum strain USDA 110 (AF363150.1), Sinorhizobium meliloti strain SEMIA 116 (FJ025128.1), Rhizobium etli

After $48 \mathrm{~h}$ of incubation, 66 and $48 \mathrm{mg} \mathrm{L}^{-1}$ of sulcotrione were degraded for an initial concentration of 100 and $200 \mathrm{mg} \mathrm{L}^{-1}$, respectively, corresponding to a degradation rate of 66 and $24 \%$. For these two concentrations, sulcotrione biodegradation was completed after 5 days of incubation. However, at the highest concentration $\left(400 \mathrm{mg} \mathrm{L}^{-1}\right)$, SR1 strain was not able to degrade anymore sulcotrione.

\section{Degradation of other triketone herbicides by Bradyrhizobium sp. SR1}

The ability of SR1 strain to degrade other synthetic (mesotrione and tembotrione) or natural triketones (leptospermone) was investigated in resting cell experiments showing that SR1 was only able to degrade mesotrione. However, the time required to get the full disappearance of $35 \mathrm{mg} \mathrm{L}^{-1}$ mesotrione (i.e., 20 days) was ten times longer than that required to dissipate the same quantity of sulcotrione (i.e., 2 days) under the same conditions. Kinetics of first order was also observed $(C=$ $102 \mathrm{e}^{-0.255 t}, R^{2}=0.993, n=3$ ) with a half-life time estimated to be about 3 days (Supplementary data Fig. 1-B).
CFN 42 (REU28916), Sphingomonas wittichii RW1 16S (NR 074268.1), Burkholderia pseudomallei (NR_074340.1), Ralstonia pickettii DSM 6297T (LN681565.1), Xanthomonas oryzae strain LMG 5047 (NR 026319.1), Escherichia coli DH5- $\alpha$ (KC768803.1), Pantoea ananatis strain CSA37 (KM091726.1), Pantoea ananatis LMG 20103 (NR_103927.1), Pseudomonas aeruginosa strain DSM 50071 (NR_ 026078.1), Pseudomonas sp. 1OP (JF303892.1), Bacillus sp. MES11(EU864320.1), Bacillus macroides (AF157696), Staphylococcus aureus strain ATCC (NR 115606.1), and Lactobacillus salivarius strain ATCC 11741(AF089108.2)

Chromatographic analysis clearly showed that mesotrione biotransformation resulted in the generation of MNBA and AMBA, the two known mesotrione by-products (Durand et al. 2006). MNBA (ESI $m / z$ 244) and AMBA (ESI $m / z$ 214) appeared after about $24 \mathrm{~h}$ of incubation and then was accumulated in the medium up to 20 and $6 \mathrm{mg} \mathrm{L}^{-1}$, respectively, by the end of the experiment. The cumulative profiles of metabolites during mesotrione transformation confirmed a quantitative transformation of mesotrione into MNBA and AMBA (Fig. 3b). Resting cell experiments showed that none of these two metabolites could be degraded by SR1.

\section{Microbial toxicity of sulcotrione and mesotrione metabolites}

In order to estimate the microbial toxicity of sulcotrione and mesotrione metabolites formed by Bradyrhizobium sp. SR1, HPPD inhibition capacity was assessed from the supernatants of resting cells using a colorimetric bioassay. The bioassay principle is that HPPD inhibitors decreased the ability of a recombinant $E$. coli clone to produce a melanine-like pigment resulting from tyrosine catabolism through HPP and 
A

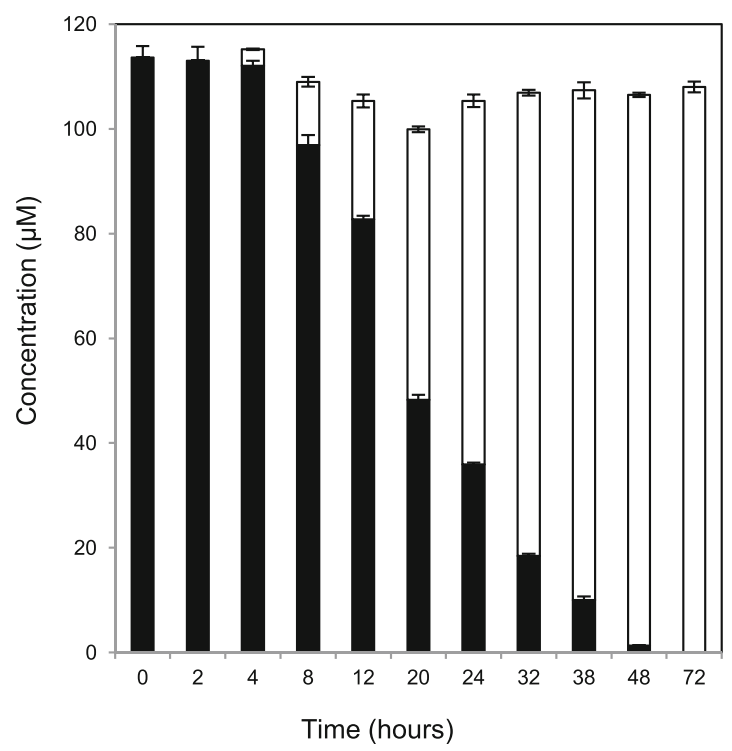

B

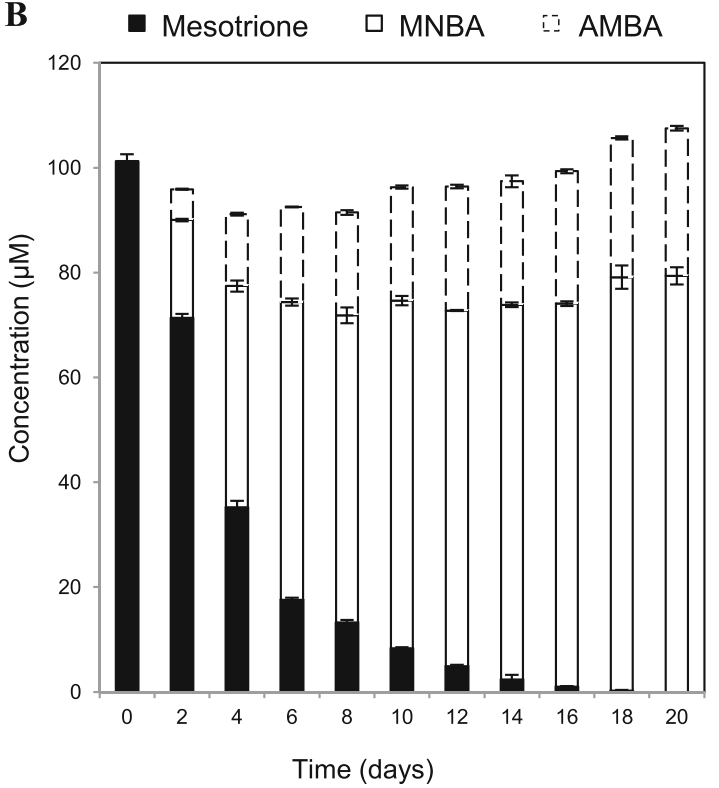

Fig. 3 Degradation kinetics of a sulcotrione and $\mathbf{b}$ mesotrione by Bradyrhizobium sp. SR1 in resting cell experiments. Cumulative formation of metabolites during sulcotrione and mesotrione degradation is represented. Standard deviations are indicated $(n=3)$

homogentisic acid. As expected, at T0, similar HPPD inhibition capacities were observed in SR1 culture and in the noninoculated sulcotrione control (Fig. 5a). For 4 h, the HPPD inhibition capacity of the SR1 supernatant aliquots from sulcotrione resting cells was stable averaging $18 \pm 1.30 \%$. Thereafter, the HPPD inhibition decreased with time being negligible after $48 \mathrm{~h}$ of incubation. A significant linear regression $\left(R^{2}=0.92\right)$ between the decrease in sulcotrione and HPPD inhibition was observed (Fig. 5b). Similarly, no HPPD inhibition was observed with SR1 supernatant aliquots from mesotrione resting cells after 20 days of incubation when no more mesotrione remained (data not shown).

\section{Genetic localization of sulcotrione degradation in Bradyrhizobium sp. SR1}

Attempts were done to identify the genetic localization of sulcotrione degradation in SR1. Keeping in mind that pesticide degradation by soil bacteria is often supported by large catabolic plasmids, this hypothesis was explored. Thus, a plasmid profile of the strain SR1 was performed and revealed the presence of a unique plasmid. Its size was estimated to be superior to $50 \mathrm{~kb}$ in comparison with a plasmid of known size (Fig. 6). Curing experiments were performed by cultivating $\mathrm{SR} 1$ isolate on a rich medium in the absence of selection pressure exerted by sulcotrione. After about 80 generations, the strain did neither lose its plasmid nor its capacity to degrade sulcotrione in resting cell experiments. In addition, the plasmid pSR1, labeled with Tn5, was successfully transferred to E. coli by electroporation (Fig. 6). However, transformed E. coli were not able to degrade sulcotrione in resting cell experiment. Furthermore, the insertion of the labeled plasmid into a nondegrading B. japonicum $\mathrm{G} 49$ was also assessed, but this transformation was unsuccessful.

\section{Discussion}

In this study, we report the isolation of SR1, a sulcotrionedegrading strain isolated from the soil of Perpignan, which was regularly exposed to this herbicide and known to host a microflora able to transform sulcotrione to CHD and CMBA (Chaabane et al. 2008). SR1 was able to use sulcotrione as the sole source of carbon and energy for its growth. 16S rRNA phylogeny analysis indicated that SR 1 strain belongs to the $\alpha$ Proteobacteria class, Bradyrhizobium genus and was named Bradyrhizobium sp. SR1. Interestingly, although this genus is mainly known for $\mathrm{N}$-fixing symbiosis developed with leguminous plants, several studies have reported the involvement of various Bradyrhizobium strains in pesticide degradation

Fig. 4 Proposed scheme for the degradation of sulcotrione by Bradyrhizobium sp. SR1

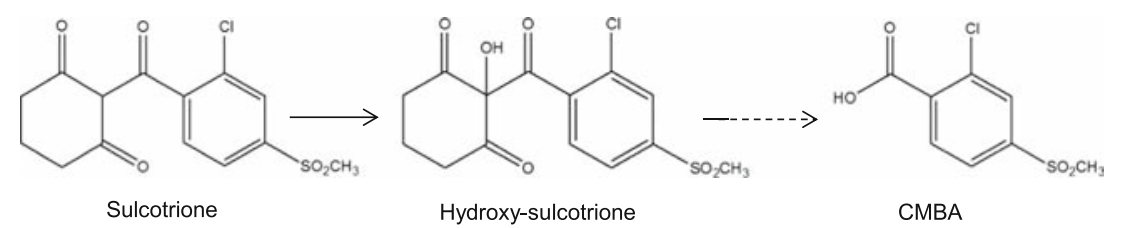


A

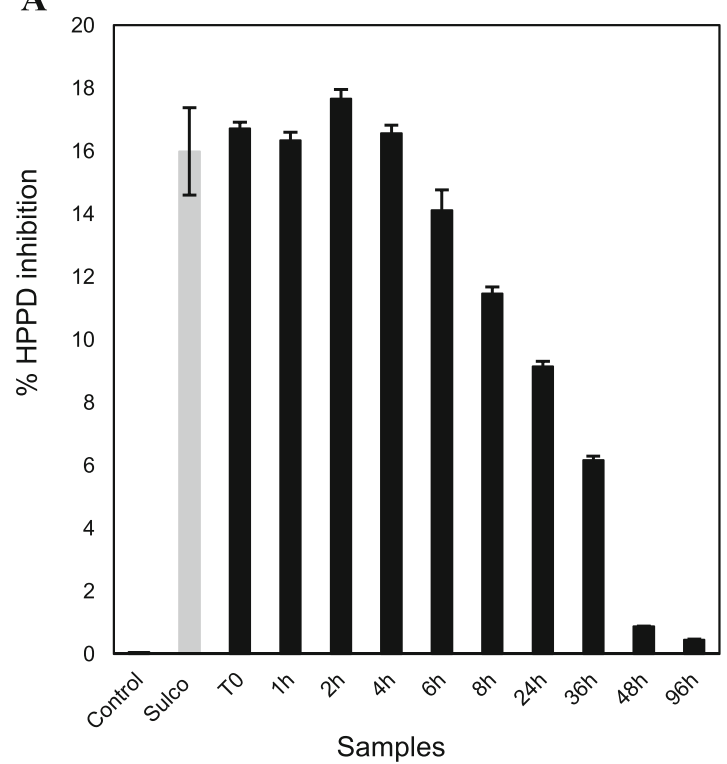

Fig. 5 a HPPD inhibitor capacity of SR1 resting cells incubated with $35 \mathrm{mg} \mathrm{L}^{-1}$ of sulcotrione and collected at different time (T0 to T96h) using colorimetric free cell bioassay. Control: negative control including SR1 resting cells incubated without sulcotrione. Sulco: noninoculated

including herbicides such as 2,4-D (Kamagata et al. 1997; Huong et al. 2007), pentoxazone (Satsuma et al. 2000), simazine (Ozawa et al. 2004), and insecticide like methoxychlor (Satsuma et al. 2013).

Our work has demonstrated that SR1 was not only able to degrade sulcotrione but also mesotrione another herbicide belonging to the $\beta$-triketone family. To our best knowledge, this is the first report describing the isolation and the characterization of a bacterial strain able to degrade these two herbicides from triketone class. Up to now, only one bacterial isolate,

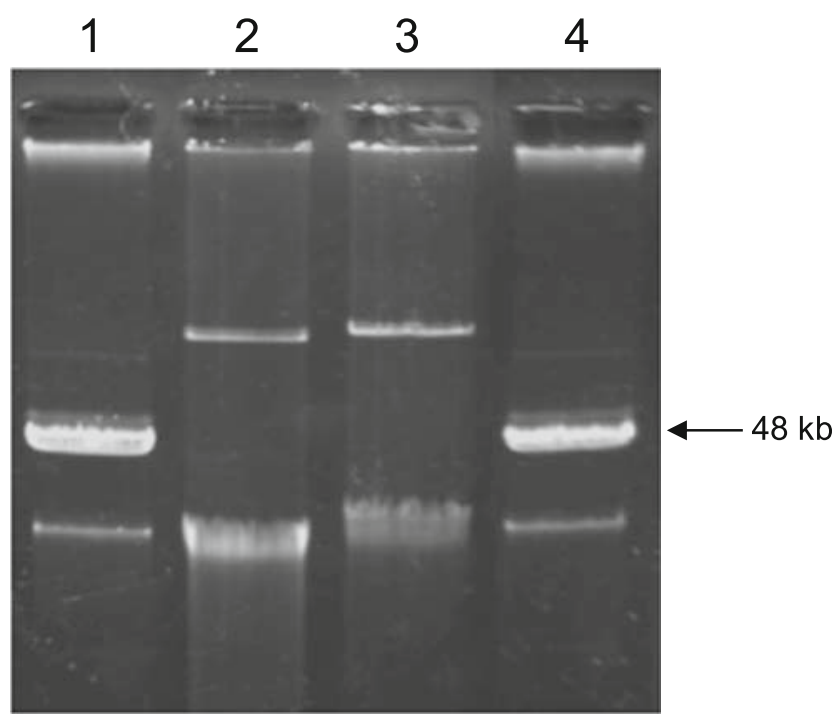

Fig. 6 Plasmid profiles from (1 and 4) Sphingomonas sp. SH., used as molecular weight marker, (2) Bradyrhizobium sp. SR1, and (3) E. coli pSR1::EZTn5. The size of the plasmid is indicated in $\mathrm{kb}$
B

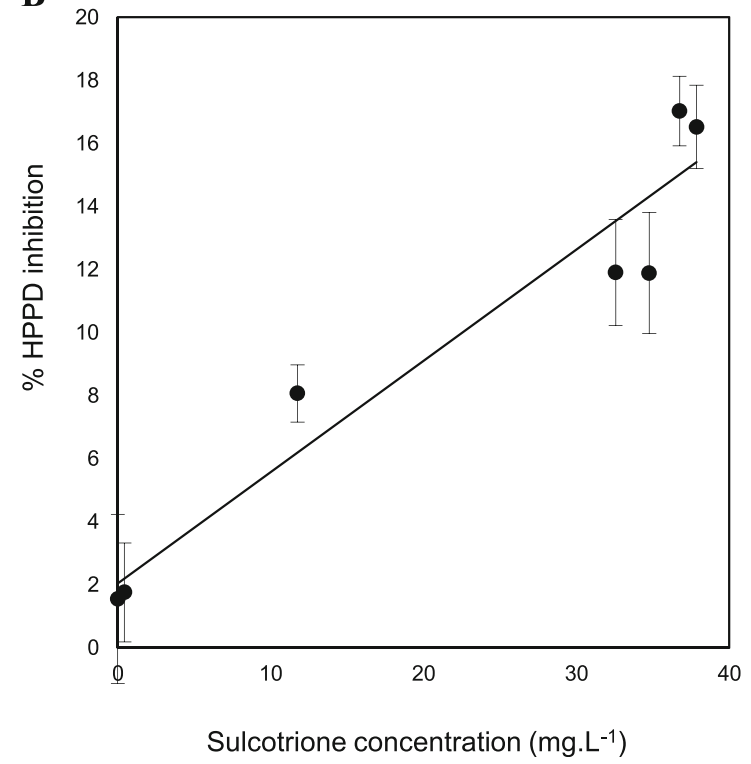

sulcotrione-positive control at a concentration of $35 \mathrm{mg} \mathrm{L}^{-1}$. Standard deviations are indicated $(n=3)$. b Linear regression between sulcotrione dissipation and HPPD inhibition

Pseudomonas sp. 1OP, also isolated from the soil of Perpignan, was shown to degrade sulcotrione and to use it as sole carbon and energy sources under aerobic conditions (Calvayrac et al. 2012). One could observe that, as previously shown for Pseudomonas sp. 1OP by these authors, sulcotrione degradation with SR1 was leading to equimolar formation of CMBA metabolite. However, during the time course of sulcotrione degradation, we observed the transient accumulation of hydroxy-sulcotrione. This compound was previously detected as a metabolite resulting from abiotic degradation (i.e., photocatalysis treatment) of sulcotrione (Jovic et al. 2013). This observation led us to propose that SR1 degradation pathway is organized in two-step process: sulcotrione being first transformed to hydroxy-sulcotrione through oxidation, which is then transformed to CMBA and consecutively accumulated as a dead-end metabolite (Fig. 4). This is in accordance with Chaabane et al. (2008) reporting the accumulation of CMBA in the soil of Perpignan as a result of microbial transformation of sulcotrione. However, CHD the other degradation product of sulcotrione observed in the soil of Perpignan (Chaabane et al. 2008) was not detected in the culture media of strain SR1 neither by HPLC/UV nor by HPLC/mass spectrometry. Similar observation was done for Pseudomonas sp. 1OP (Calvayrac et al. 2012). As previously suggested, this discrepancy might be caused by abiotic transformation of $\mathrm{CHD}$ or to $\beta$-diketone oxidation catalyzed by enzymatic $\mathrm{C}-\mathrm{C}$ bound breaking (Calvayrac et al. 2012). CMBA and CHD degrading tests have been carried out in resting cell experiments showing that SR1 was unable to degrade these two metabolites. SR1 was not able to degrade 
CHD probably because degradation pathway of this metabolite is inducible.

To date, several mesotrione-degrading bacteria have been isolated from different environments (i.e., water, soil, and clouds), but only a limited number of strains, all belonging to Bacillus genus, used this herbicide as a carbon source (Durand et al. 2006; Batisson et al. 2009; Pileggi et al. 2012). For Bacillus sp. 3B6, the major pathway of mesotrione degradation was initiated by a reduction of the nitro group of mesotrione resulting in the formation of several transformation products (M2, M3, and M4 as described in Supplementary data Fig. 2) leading to the formation of AMBA (Durand et al. 2010). A minor pathway leading almost directly to AMBA by an oxidative cleavage of mesotrione followed by a reduction of the nitro group was also observed. Although in the literature MNBA and AMBA have been described as the two main metabolites of mesotrione (Alferness and Wiebe 2002), MNBA was barely detected in Bacillus sp. 3B6 either because it was formed in an amount below its detection limit or because it was transformed since its formation in the medium (Durand et al. 2010). Similar mesotrionedegrading pathway was observed in Bacillus sp. MES11 (Batisson et al. 2009). According to our observations, the mesotrione degradation pathway of Bradyrhizobium sp. SR1 differed from that of Bacilli degraders, since (i) the three metabolites (M2, M3, and M4) resulting from the reduction of the nitro group of mesotrione were not detected during mesotrione degradation and (ii) both MNBA and AMBA were detected in the culture media. Additionally, resting cell experiments showed, that contrarily to Bacilli mesotrionedegrading strains, SR1 did not transform MNBA to AMBA. To explain this discrepancy, one could hypothesize, on the one hand, that SR1 strain harbors two distinct mesotrionedegradation pathways resulting in the formation of both MNBA and AMBA. On the other hand, mesotrione could be transformed into MNBA following the minor mesotrionedegradation pathway previously described in Bacilli strains, which is then transformed to AMBA (Supplementary data Fig. 2). Further studies are necessary to determine the pathway of degradation of mesotrione in strain SR1.

Although SR1 was able to degrade both sulcotrione and mesotrione, sulcotrione rate of degradation was ten times higher than that of mesotrione. This reveals that the selection driven by sulcotrione exposure led to the selection of SR1 harboring degrading enzymes highly specific for this herbicide. Among the other triketones tested, SR1 was only able to degrade mesotrione, which is having a chemical structure diverging from sulcotrione only by one substituent, $-\mathrm{NO}_{2}$ instead of $-\mathrm{Cl}$ in position 2 of the aromatic group. Concerning tembotrione, the presence of 2,2,2-trifluoroethoxymethyl group in position 3 on the aromatic ring may contribute to the steric hindrance of the benzoyl 3-substituent on the enzymatic binding (Calvayrac et al. 2014) compromising its interaction with the catalytic site of SR1-degrading enzymes. On the contrary, the absence of the aromatic ring in the leptospermone may dramatically reduce its affinity for SR1 catabolic enzymes. A few number of pesticide-degrading strains are known to metabolize molecules belonging to the same family depending on the affinity of the degradingenzyme to the pesticide (Karns et al. 1986; Strong et al. 2002; Karpouzas et al. 2005). As an example, biochemical studies carried out with Mycobacterium brisbanense strain JK1, a diuron-degrading bacterial isolate, showed that PuhA displayed the highest affinity for diuron, while this enzyme had lower affinities for other phenylureas such as chlorotoluron, isoproturon, linuron, and monolinuron (Khurana et al. 2009). It was suggested that the substrate specificity of PuhA was predominantly determined by steric factors, which could be the case for the enzymatic triketone degradation system of SR1.

The SR1 strain was not able to degrade sulcotrione at high concentrations. This might be explained by a possible dosedepending toxic effect of sulcotrione most likely resulting from the inhibition of a potential HPPD enzyme implicated in tyrosine metabolism of SR1. The presence of an hppd gene in B. japonicum USDA110 phylogenetically related to SR1 (Fig. 2) supports this hypothesis. Furthermore, the toxicity of triketone molecules and their related metabolites was estimated by monitoring HPPD inhibition. As expected, the obtained results confirmed that sulcotrione and mesotrione toxicity due to HPPD inhibition was mainly linked to parent molecule and revealed that the main metabolites displayed weak HPPD inhibitory capacities. These last observations are in contradiction with a previous study showing that CMBA metabolite displayed a higher toxicity than sulcotrione using Microtox assays with $V$. fischeri (Bonnet et al. 2008). Therefore, one could conclude that SR1-degrading activity is, on the one hand, beneficial to soil living organisms having sulcotrionesensitive HPPD enzymes by removing the exposure to sulcotrione but, on the other hand, deleterious to soil organisms sensitive to sulcotrione metabolites, such as CMBA, which is accumulated during sulcotrione transformation. This ambivalent contribution of pesticide degraders was already reported for a range of pesticides that are transformed to toxic intermediates (i.e., phenylurea transformation to aniline derivatives, for review, see Hussain et al. 2015). For environmental safety, the ideal situation would be to have a synergetic cooperation between different microbial populations able to completely mineralize sulcotrione in soil.

Genes coding for degrading enzymes involved in different pesticide metabolisms, such as 2,4-D, isoproturon, and atrazine, are well known to form catabolic islands on plasmids spread all over the degrading community by horizontal gene transfer (Assinder and Williams 1990; Udikovic-Kolic et al. 2012; Gu et al. 2013). Recently, Calvayrac et al. (2014) showed that genetic system responsible for sulcotrione 
degradation by Pseudomonas sp. 1OP was also plasmid borne. Several attempts were done in this work to determine if the degrading genes were localized on the large plasmid harbored by SR1. We showed that SR1 plasmid was not eliminated by curing experiment carried out on rich medium and that sulcotrione-degrading ability was maintained without pesticide selection pressure. The stability of this plasmid might be explained by the presence of essential genes for SR1 survival and growth. This is in agreement with previous studies showing that plasmids cannot be cured in rhizobia mainly because of the presence of genes essential for freeliving growth (Finan et al. 1986). Although pSR1::Tn5 was successfully transferred to $E$. coli, the transconjugant was not able to degrade sulcotrione. Based on this result, one could hypothesize that either catabolic genes are not plasmid borne or, for some reasons, genes located on SR1 plasmid are not expressed in the transconjugant.

\section{Conclusion}

We report the isolation and characterization of Bradyrhizobium sp. SR1 from an agricultural soil, which is able to biotransform two triketone herbicides. The dissipation of sulcotrione and mesotrione led to the accumulation of different known by-products, CMBA and MNBA/AMBA. Interestingly, hydroxysulcotrione was identified as a new metabolite, and a metabolic pathway was proposed. Further studies are required to identify and describe genes coding for enzymes involved in the transformation of these two triketones.

Acknowledgments This work was supported by the French "Agence National de la Recherche" under TRICETOX project, number ANR-13CESA-0002. Leptospermone was kindly provided by Franck E. Dayan (Natural Products Utilization Research Unit, USDA). The authors would like to thank Nathalie Bontemps (LCBE-CRIOBE-USR 3278 CNRS EPHE, UPVD) for sulcotrione metabolite analysis. The authors declare that they have no conflict of interest. The funders had no role in study design, data collection and analysis, decision to publish, or preparation of the manuscript.

Compliance with ethical standards All authors agreed to be listed and have approved of the manuscript, its content, and its submission to Environmental Science and Pollution Research. It has not been submitted or published elsewhere, whether partly or fully. All authors are in agreement with the ethical rules of ESPR.

\section{References}

Alferness P, Wiebe L (2002) Determination of mesotrione residues and metabolites in crops, soil, and water by liquid chromatography with fluorescence detection. J Agric Food Chem 50(14):3926-3934

Anderson JPE (1984) Herbicide degradation in soil-influence of microbial biomass. Soil Biol Biochem 16(5):483-489
Arbeli Z, Fuentes CL (2007) Accelerated biodegradation of pesticides: an overview of the phenomenon, its basis and possible solutions; and a discussion on the tropical dimension. Crop Prot 26(12):1733-1746

Assinder SJ, Williams PA (1990) The TOL plamids - determinants of the catabolism of toluene and the xylenes. Adv Microb Physiol 31:1-69

Batisson I, Crouzet O, Besse-Hoggan P, Sancelme M, Mangot J-F, Mallet C, Bohatier J (2009) Isolation and characterization of mesotrionedegrading Bacillus sp from soil. Environ Pollut 157(4):1195-1201

Bonnet JL, Bonnemoy F, Dusser M, Bohatier J (2008) Toxicity assessment of the herbicides sulcotrione and mesotrione toward two reference environmental microorganisms: Tetrahymena pyriformis and Vibrio fischeri. Arch Environ Contam Toxicol 55(4):576-583

Calvayrac C, Martin-Laurent F, Faveaux A, Picault N, Panaud O, Coste C-M, Chaabane H, Cooper J-F (2012) Isolation and characterisation of a bacterial strain degrading the herbicide sulcotrione from an agricultural soil. Pest Manag Sci 68(3):340-347

Calvayrac C, Romdhane S, Barthelmebs L, Rocaboy E, Cooper J-F, Bertrand C (2014) Growth abilities and phenotype stability of a sulcotrione-degrading Pseudomonas sp. isolated from soil. Int Biodeterior Biodegrad 91:104-110

Chaabane H, Cooper JF, Azouzi L, Coste CM (2005) Influence of soil properties on the adsorption-desorption of sulcotrione and its hydrolysis metabolites on various soils. J Agric Food Chem 53(10): 4091-4095

Chaabane H, Vulliet E, Calvayrac C, Coste CM, Cooper JF (2008) Behaviour of sulcotrione and mesotrione in two soils. Pest Manag Sci 64(1):86-93

Crouzet O, Batisson I, Besse-Hoggan P, Bonnemoy F, Bardot C, Poly F, Bohatier J, Mallet C (2010) Response of soil microbial communities to the herbicide mesotrione: a dose-effect microcosm approach. Soil Biol Biochem 42(2):193-202

Dayan FE, Duke SO, Sauldubois A, Singh N, McCurdy C, Cantrell C (2007) p-Hydroxyphenylpyruvate dioxygenase is a herbicidal target site for beta-triketones from Leptospermum scoparium. Phytochemistry 68(14):2004-2014

Devers M, El Azhari N, Kolic N-U, Martin-Laurent F (2007) Detection and organization of atrazine-degrading genetic potential of seventeen bacterial isolates belonging to divergent taxa indicate a recent common origin of their catabolic functions. FEMS Microbiol Lett 273(1):78-86

Durand S, Amato P, Sancelme M, Delort AM, Combourieu B, BesseHogan P (2006) First isolation and characterization of a bacterial strain that biotransforms the herbicide mesotrione. Lett Appl Microbiol 43(2):222-228

Durand S, Sancelme M, Besse-Hoggan P, Combourieu B (2010) Biodegradation pathway of mesotrione: complementarities of NMR, LC-NMR and LC-MS for qualitative and quantitative metabolic profiling. Chemosphere 81(3):372-380

Dyson JS, Beulke S, Brown CD, Lane MCG (2002) Adsorption and degradation of the weak acid mesotrione in soil and environmental fate implications. J Environ Qual 31(2):613-618

Finan TM, Kunkel B, Devos GF, Signer ER (1986) 2nd symbiotic mehaplasmid in Rhizobium meliloti carrying exopolysaccharide and thiamine synthesis genes. J Bacteriol 167(1):66-72

Goujon E, Sta C, Trivella A, Goupil P, Richard C, Ledoigt G (2014) Genotoxicity of sulcotrione pesticide and photoproducts on Allium cepa root meristem. Pestic Biochem Physiol 113:47-54

Gürtler V, Stanisich V (1996) New approaches to typing and identification of bacteria using the 16S-23S rDNA spacer region. Microbiol 142(1):3-16

Gu T, Zhou C, Sorensen SR, Zhang J, He J, Yu P, Yan X, Li S (2013) The novel bacterial N-demethylase PdmAB is responsible for the initial step of N, N-dimethyl-substituted phenylurea herbicide degradation. Appl Environ Microbiol 79(24):7846-7856

Huong NL, Itoh K, Suyama K (2007) Diversity of 2,4dichlorophenoxyacetic acid (2,4-D) and 2,4,5-trichlorophenoxyacetic acid (2,4,5-T)-degrading bacteria in Vietnamese soils. Microbes Environ 22(3):243-256 
Hussain S, Arshad M, Springael R, Sørensen SR, Bending GD, DeversLamrani M, Maqboola Z, Martin-Laurent F (2015) Abiotic and biotic processes governing the fate of phenylurea herbicides in soils: a review. Crit Rev Environ Sci Technol. doi:10.1080/10643389.2014. 1001141

Joly P, Bonnemoy F, Charvy J-C, Bohatier J, Mallet C (2013) Toxicity assessment of the maize herbicides S-metolachlor, benoxacor, mesotrione and nicosulfuron, and their corresponding commercial formulations, alone and in mixtures, using the Microtox ${ }^{\circledR}$ test. Chemosphere 93(10):2444-2450

Jovic M, Manojlovic D, Stankovic D, Dojcinovic B, Obradovic B, Gasic U, Roglic G (2013) Degradation of triketone herbicides, mesotrione and sulcotrione, using advanced oxidation processes. J Hazard Mater 260:1092-1099

Kamagata Y, Fulthorpe RR, Tamura K, Takami H, Forney LJ, Tiedje JM (1997) Pristine environments harbor a new group of oligotrophic 2, 4-dichlorophenoxyacetic acid-degrading bacteria. Appl Environ Microbiol 63(6):2266-2272

Karns JS, Mulbry WW, Nelson JO, Kearney PC (1986) Metabolism of carbofuran by a pure bacterial culture. Pestic Biochem Physiol 25(2):211-217

Karpouzas DG, Fotopoulou A, Menkissoglu-Spiroudi U, Singh BK (2005) Non-specific biodegradation of the organophosphorus pesticides, cadusafos and ethoprophos, by two bacterial isolates. FEMS Microbiol Ecol 53(3):369-378

Khurana JL, Jackson CJ, Scott C, Pandey G, Horne I, Russell RJ, Herlt A, Easton CJ, Oakeshott JG (2009) Characterization of the phenylurea hydrolases A and B: founding members of a novel amidohydrolase subgroup. Biochem J 418:431-441

Lee DL, Prisbylla MP, Cromartie TH, Dagarin DP, Howard SW, Provan WM, Ellis MK, Fraser T, Mutter LC (1997) The discovery and structural requirements of inhibitors of p-hydroxyphenylpyruvate dioxygenase. Weed Sci 45(5):601-609

Ma R, Kaundun SS, Tranel PJ, Riggins CW, McGinness DL, Hager AG, Hawkes T, McIndoe E, Riechers DE (2013) Distinct detoxification mechanisms confer resistance to mesotrione and atrazine in a population of waterhemp. Plant Physiol 163(1):363-377

Meazza G, Scheffler BE, Tellez MR, Rimando AM, Romagni JG, Duke SO, Nanayakkara D, Khan IA, Abourashed EA, Dayan FE (2002) The inhibitory activity of natural products on plant phydroxyphenylpyruvate dioxygenase. Phytochemistry 60(3):281-288

Mitchell G, Bartlett DW, Fraser TEM, Hawkes TR, Holt DC, Townson JK, Wichert RA (2001) Mesotrione: a new selective herbicide for use in maize. Pest Manag Sci 57(2):120-128

Olchanheski LR, Dourado MN, Beltrame FL, Zielinski AAF, Demiate IM, Pileggi SAV, Azevedo RA, Sadowsky MJ, Pileggi M (2014) Mechanisms of tolerance and high degradation capacity of the herbicide mesotrione by Escherichia coli strain DH5-alpha. PLoS ONE 9(6). doi:10.1371/journal.pone.0099960

Ozawa T, Yoshida R, Wakashiro Y, Hase H (2004) Improvement of simazine degradation by inoculation of corn and soybean plants with rhizobacteria. Soil Sci Plant Nutr 50(8):1295-1299

Perriere G, Gouy M (1996) WWW-Query: an on-line retrieval system for biological sequence banks. Biochimie 78(5):364-369

Pileggi M, Veiga Pileggi SA, Olchanheski LR, Garbugio da Silva PA, Gonzalez AMM, Koskinen WC, Barber B, Sadowsky MJ (2012) Isolation of mesotrione-degrading bacteria from aquatic environments in Brazil. Chemosphere 86(11):1127-1132
Rocaboy-Faquet E, Noguer T, Romdhane S, Bertrand C, Dayan FE, Barthelmebs L (2014) Novel bacterial bioassay for a highthroughput screening of 4-hydroxyphenylpyruvate dioxygenase inhibitors. Appl Microbiol Biotechnol 98(16):7243-7252

Rouchaud J, Neus O, Bulcke R, Cools K, Eelen H (1998) Sulcotrione soil metabolism in summer corn crops. Bull Environ Contam Toxicol 61(5):669-676

Rousseaux S, Hartmann A, Soulas G (2001) Isolation and characterisation of new Gram-negative and Gram-positive atrazine degrading bacteria from different French soils. FEMS Microbiol Ecol 36(2-3): 211-222

Satsuma K, Hayashi O, Sato K, Ohyama K, Maki S, Hashimura M, Kato Y (2000) Isolation of pentoxazone-transforming microorganisms from soil: their characteristics and metabolites. J Pestic Sci 25(4): 357-364

Satsuma K, Masuda M, Sato K (2013) A role of Bradyrhizobium elkanii and closely related strains in the degradation of methoxychlor in soil and surface water environments. Biosci Biotechnol Biochem 77(11):2222-2227

Schulz A, Ort O, Beyer P, Kleinig H (1993) SC-0051, a 2-benzoyl-cyclohexane-1,3-dione bleaching herbicide, is a potent inhibitor of the enzyme p-hydroxyphenylpyruvate dioxygenase. FEBS Lett 318(2):162-166

Shaner DL (2004) Herbicide safety relative to common targets in plants and mammals. Pest Manag Sci 60(1):17-24

Siehl DL, Tao Y, Albert H, Dong Y, Heckert M, Madrigal A, LincolnCabatu B, Lu J, Fenwick T, Bermudez E, Sandoval M, Horn C, Green JM, Hale T, Pagano P, Clark J, Udranszky IA, Rizzo N, Bourett T, Howard RJ, Johnson DH, Vogt M, Akinsola G, Castle LA (2014) Broad 4-hydroxyphenylpyruvate dioxygenase inhibitor herbicide tolerance in soybean with an optimized enzyme and expression cassette. Plant Physiol 166(3):1162-1176

Strong LC, Rosendahl C, Johnson G, Sadowsky MJ, Wackett LP (2002) Arthrobacter aurescens TC1 metabolizes diverse s-triazine ring compounds. Appl Environ Microbiol 68(12):5973-5980

Thompson JD, Gibson TJ, Plewniak F, Jeanmougin F, Higgins DG (1997) The CLUSTAL X windows interface: flexible strategies for multiple sequence alignment aided by quality analysis tools. NAR 25(24):4876-4882

Topp E (2003) Bacteria in agricultural soils: diversity, role and future perspectives. Can J Soil Sci 83(3):303-309

Udikovic-Kolic N, Scott C, Martin-Laurent F (2012) Evolution of atrazine-degrading capabilities in the environment. Appl Microbiol Biotechnol 96(5):1175-1189

Van der Meer JR, Devos WM, Harayama S, Zehnder AJB (1992) Molecular mechanisms of genetic adaptation to xenobiotic compounds. Microbiol Rev 56(4):677-694

Vincent JM (1970) A manual for the practical study of root-nodule bacteria. International biological programme handbook No. 15, Blackwell Science Publications. Oxford, England

Walker A, Welch SJ (1991) Enhanced degradation of some soil-applied herbicides. Weed Res 31(1):49-57

Wu N, Jin Y, Jin F, Tan Y, Tao H, Zheng M, Chen R, Liu K, Gao M (2011) Effects of sulcotrione 2-(2-chloro-4-mesylbenzoyl)-cyclohexane-1, 3 -dione on enzymes involved in tyrosine catabolism and the extent of the resulting tyrosinemia and its relationship with corneal lesions in rats. Pestic Biochem Physiol 99(2):162-169 